\title{
Family Medicine and Community Health \\ Fundamentals of case study research in family medicine and community health
}

\author{
Sergi Fàbregues, ${ }^{1}$ Michael D Fetters ${ }^{2}$
}

To cite: Fàbregues $\mathrm{S}$, Fetters MD. Fundamentals of case study research in family medicine and community health. Fam Med Com Health 2019;7:e000074. doi:10.1136/ fmch-2018-000074

Received 30 November 2018 Revised 07 December 2018 Accepted 23 January 2019
Check for updates

(c) Author(s) (or their employer(s)) 2019. Re-use permitted under CC BY-NC. No commercial re-use. See rights and permissions. Published by BMJ.

${ }^{1}$ Department of Psychology and Education, Universitat Oberta de Catalunya, Barcelona, Spain ${ }^{2}$ Department of Family Medicine, University of Michigan, Ann Arbor, Michigan, USA

Correspondence to Dr Sergi Fàbregues, Department of Psychology and Education, Universitat Oberta de Catalunya, Rambla del Poblenou, 156, 08018, Barcelona, Spain; sfabreguesf@uoc.edu

\begin{abstract}
The aim of this article is to introduce family medicine researchers to case study research, a rigorous research methodology commonly used in the social and health sciences and only distantly related to clinical case reports. The article begins with an overview of case study in the social and health sciences, including its definition, potential applications, historical background and core features. This is followed by a 10-step description of the process of conducting a case study project illustrated using a case study conducted about a teaching programme executed to teach international family medicine resident learners sensitive examination skills. Steps for conducting a case study include (1) conducting a literature review; (2) formulating the research questions; (3) ensuring that a case study is appropriate; (4) determining the type of case study design; (5) defining boundaries of the case(s) and selecting the case(s); (6) preparing for data collection; (7) collecting and organising the data; (8) analysing the data; (9) writing the case study report; and (10) appraising the quality. Case study research is a highly flexible and powerful research tool available to family medicine researchers for a variety of applications.
\end{abstract}

\section{SIGNIFICANCE STATEMENT}

Given their potential for answering 'how' and 'why' questions about complex issues in their natural setting, case study designs are being increasingly used in the health sciences. Conducting a case study can, however, be a complex task because of the possibility of combining multiple methods and the need to choose between different types of case study designs. In order to introduce family medicine and community health researchers to the fundamentals of case study research, this article reviews its definition, potential applications, historical background and main characteristics. It follows on with a practical, step-by-step description of the case study process that will be useful to researchers interested in implementing this research design in their own practice.

\section{INTRODUCTION}

This article provides family medicine and community health researchers a concise resource to conduct case study research. The article opens with an overview of case study in the social and health sciences, including its definition, potential applications, historical background and core features. This is followed by a 10-step description of the process of conducting a case study project, as described in the literature. These steps are illustrated using a case study about a teaching programme executed to teach international medical learners sensitive examination skills. The article ends with recommendations of useful articles and textbooks on case study research.

\section{ORIGINS OF CASE STUDY RESEARCH}

Case study is a research design that involves an intensive and holistic examination of a contemporary phenomenon in a real-life setting. ${ }^{1-3}$ It uses a variety of methods and multiple data sources to explore, describe or explain a single case bounded in time and place (ie, an event, individual, group, organisation or programme). A distinctive feature of case study is its focus on the particular characteristics of the case being studied and the contextual aspects, relationships and processes influencing it. ${ }^{4}$ Here we do not include clinical case reports as these are beyond the scope of this article. While distantly related to clinical case reports commonly used to report unusual clinical case presentations or findings, case study is a research approach that is frequently used in the social sciences and health sciences. In contrast to other research designs, such as surveys or experiments, a key strength of case study is that it allows the researcher to adopt a holistic approach-rather than an isolated approach-to the study of social phenomena. As argued by Yin, ${ }^{3}$ case studies are particularly suitable for answering 'how' research questions (ie, how a treatment was received) as well as 'why' research questions (ie, why the treatment produced the observed outcomes).

Given its potential for understanding complex processes as they occur in their natural setting, case study increasingly is used 
in a wide range of health-related disciplines and fields, including medicine,${ }^{5}$ nursing ${ }^{6}$ health services research ${ }^{1}$ and health communication. ${ }^{7}$ With regard to clinical practice and research, a number of authors ${ }^{158}$ have highlighted how insights gained from case study designs can be used to describe patients' experiences regarding care, explore health professionals' perceptions regarding a policy change, and understand why medical treatments and complex interventions succeed or fail.

In anthropology and sociology, case study as a research design was introduced as a response to the prevailing view of quantitative research as the primary way of undertaking research. ${ }^{9}$ From its beginnings, social scientists saw case study as a method to obtain comprehensive accounts of social phenomena from participants. In addition, it could complement the findings of survey research. Between the 1920 s and 1960s, case study became the predominant research approach among the members of the Department of Sociology of the University of Chicago, widely known as 'The Chicago School'. ${ }^{11}$ During this period, prominent sociologists, such as Florian Znaniecki, William Thomas, Everett C Hughes and Howard S Becker, undertook a series of innovative case studies (including classical works such as The Polish peasant in Europe and America or Boys in White), which laid the foundations of case study designs as implemented today.

In the 1970 s, case study increasingly was adopted in the USA and UK in applied disciplines and fields, such as education, programme evaluation and public policy research. ${ }^{12}$ As a response to the limitations of quasi-experimental designs for undertaking comprehensive programme evaluations, researchers in these disciplines saw in case studies-either alone or in combination with experimental designs-an opportunity to gain additional insights into the outcomes of programme implementation. In the mid-1980s and early 1990s, the case study approach became recognised as having its own 'logic of design' (p46) ${ }^{13}$ This period coincides with the publication of a considerable number of influential articles ${ }^{14-16}$ and textbooks ${ }^{41718}$ on case study research.

These publications were instrumental in shaping contemporary case study practice, yet they reflected divergent views about the nature of case study, including how it should be defined, designed and implemented (see $\operatorname{Yazan}^{19}$ for a comparison of the perspectives of Yin, Merriam and Stake, three leading case study methodologists). What these publications have in common is that case study revolves around four key features.

First, case study examines a specific phenomenon in detail by performing an indepth and intensive analysis of the selected case. The rationale for case study designs, rather than more expansive designs such as surveys, is that the researcher is interested in investigating the particularity of a case, that is, the unique attributes that define an event, individual, group, organisation or programme. ${ }^{2}$ Second, case study is conducted in natural settings where people meet, interact and change their perceptions over time. The use of the case study design is a choice in favour of 'maintaining the naturalness of the research situation and the natural course of events' ( $p 177) .{ }^{20}$

Third, case study assumes that a case under investigation is entangled with the context in which it is embedded. This context entails a number of interconnected processes that cannot be disassociated from the case, but rather are part of the study. The case study researcher is interested in understanding how and why such processes take place and, consequently, uncovering the interactions between a case and its context. Research questions concerning how and why phenomena occur are particularly appropriate in case study research. ${ }^{3}$

Fourth, case study encourages the researcher to use a variety of methods and data types in a single study. ${ }^{20} 21$ These can be solely qualitative, solely quantitative or a mixture of both. The latter option allows the researcher to gain a more comprehensive understanding of the case and improve the accuracy of the findings. The four above-mentioned key features of case study are shown in table 1, using the example of a mixed methods case study evaluation. ${ }^{22}$

There are many potential applications for case study research. While often misconstrued as having only an exploratory role, case study research can be used for descriptive and explanatory research $(\mathrm{p} 7-9){ }^{3}$ Family medicine and community health researchers can use case study research for evaluating a variety of educational programmes, clinical programmes or community programmes.

\section{CASE STUDY ILLUSTRATION FROM FAMILY MEDICINE}

In the featured study, Japanese family medicine residents received standardised patient instructor-based training in female breast, pelvic, male genital and prostate examinations as part of an international training collaboration to launch a new family medicine residency programme. ${ }^{22}$ From family medicine residents, trainers and staff, the authors collected and analysed data from post-training feedback, semistructured interviews and a web-based questionnaire. While the programme was perceived favourably, they noted barriers to reinforcement in their home training programme, and taboos regarding gender-specific healthcare appear as barriers to implementing a similar programme in the home institution.

\section{A STEP-BY-STEP DESCRIPTION OF THE PROCESS OF CARRYING OUT A CASE STUDY}

As shown in table 2 and illustrated using the article by Shultz $e t a l,{ }^{22}$ case study research generally includes 10 steps. While commonly conducted in this order, the steps do not always occur linearly as data collection and analysis may occur over several iterations or implemented with a slightly different order. 


\begin{tabular}{|c|c|}
\hline Feature & How the feature is reflected in the study \\
\hline In depth & $\begin{array}{l}\text { This mixed methods case study assessed a standardised patient instructor (SPI) training programme at the } \\
\text { University of Michigan that provided training in female breast, pelvic, male genital and prostate examinations } \\
\text { to Japanese family medicine residents. } \\
\text { The SPI training programme was examined in depth, focusing on its perceived acceptability and impact. }\end{array}$ \\
\hline Natural setting & $\begin{array}{l}\text { The study was undertaken in the participants' natural setting, the Department of Family Medicine of the } \\
\text { University of Michigan and the Shizuoka Family Medicine Program. } \\
\text { Individual interviews with Japanese residents, nurses and medical assistants were conducted in Japanese, } \\
\text { enabling participants to express themselves spontaneously. } \\
\text { Data were collected three times in the course of } 3 \text { years, 2010-2012. This allowed researchers to examine } \\
\text { changes in the perceptions of the participants over time. }\end{array}$ \\
\hline Focus on context & $\begin{array}{l}\text { Interviews with the medical staff of the Shizuoka Family Medicine Program and Japanese residents allowed } \\
\text { researchers to understand how Japanese sociocultural beliefs about gender, identity and sex played a role in } \\
\text { patient care delivered by residents in Japan. They also allowed researchers to determine the extent to which a } \\
\text { similar training programme in Japan would be feasible and sustainable. }\end{array}$ \\
\hline
\end{tabular}

\section{Step 1. Conduct a literature review}

During the literature review, researchers systematically search for publications, select those most relevant to the study's purpose, critically appraise them and summarise the major themes. The literature review helps researchers ascertain what is and is not known about the phenomenon under study, delineate the scope and research questions of the study, and develop an academic or practical justification for the study. ${ }^{23}$

\section{Step 2. Formulate the research questions}

Research questions critically define in operational terms what will be researched and how. They focus the study and play a key role in guiding design decisions. Key decisions include the case selection and choice of a case study design most suitable for the study. According to Fraenkel et $a l,{ }^{24}$ the key attributes of good research questions are (1) feasibility, (2) clarity, (3) significance, (4) connection to previous research identified in the literature and (5) compliance with ethical research standards.

\section{Step 3. Ensure that a case study is appropriate}

Before commencing the study, researchers should ensure that case study design embodies the most appropriate strategy for answering the study questions. The above-noted four key features-in depth examination of phenomena, naturalness, a focus on context and the use of a combination of methods-should be reflected in the research questions as well as subsequent design decisions.

\section{Step 4. Determine the type of case study design}

Researchers need to choose a specific case study design. Sometimes, researchers may define the case first (step 5), for example, in a programme evaluation, and the case may need to be defined before determining the type. Yin's ${ }^{3}$ typology is based on two dimensions, whether the study will examine a single case or multiple cases, and whether the study will focus on a single or multiple units of analysis. Figure 1 illustrates these four types of design using a hypothetical example of a programme evaluation. Table 3 shows an example of each type from the literature.

In type 1 holistic single case design, researchers examine a single programme as the sole unit of analysis. In type 2 embedded single case design, the interest is not exclusively in the programme, but also in its different subunits, including sites, staff and participants. These subunits constitute the range of units of analysis. In type 3 holistic multiple case design, researchers conduct a within and cross-case comparison of two or more programmes, each of which constitutes a single unit of analysis. A major strength of multiple case designs is that they enable researchers to develop an in depth description of each case and to identify patterns of variation and similarity between the cases. Multiple case designs are likely to have stronger internal validity and generate more insightful findings than single case designs. They do this by allowing 'examination of processes and outcomes across many cases, identification of how individual cases might be affected by different environments, and the specific conditions under which 


\begin{tabular}{|c|c|c|}
\hline Step & & Description \\
\hline 1 & $\begin{array}{l}\text { Conduct a literature } \\
\text { review. }\end{array}$ & $\begin{array}{l}\text { Follow the process of reviewing the literature: } \\
\text { search for publications, select the publications } \\
\text { that are more relevant for the study's purpose, } \\
\text { appraise them and summarise the major themes } \\
\text { identified. } \\
\text { Ensure that the literature review informs the } \\
\text { formulation of the research questions. }\end{array}$ \\
\hline 2 & $\begin{array}{l}\text { Formulate the } \\
\text { research questions. }\end{array}$ & $\begin{array}{l}\text { Formulate research questions that are feasible, } \\
\text { clear, significant, ethical and connected to } \\
\text { previous research. }\end{array}$ \\
\hline
\end{tabular}

3 Ensure that a case study is appropriate.

\section{the four key features of case study research:}

- In depth examination of phenomena.

- Naturalness.

- Focus on context.

- Use of a combination of methods.

4 Determine the type of Decide the type of case study that will be used case study design. according to Yin's typology ${ }^{3}$ :

- Holistic single case design.

- Embedded single case design.

- Holistic multiple case design.

- Embedded multiple case design.

5 Define the boundaries of the case(s) and select the case(s).

Define the case and how it fits within its broader context.

- Select the case or cases that will be investigated.

6 Prepare to collect data.

- Elaborate a case study protocol that provides a detailed description of the methods that will be used during the data collection.
- In addition to reviewing pertinent literature on epidemiology of different cancers and healthcare in Japan, the authors reviewed issues around gender and health issues. They provided a justification for conducting the case study for uniquely addressing the topic of training sensitive healthcare examinations in Japan.

- To investigate SPIs' and Japanese residents' perceptions about the training experience in the USA, and to examine the perceived impact and acceptability of performing the learnt skills from residents and other key informants after residents returned to Japan.

- As illustrated in table 1, the authors' study was conducted in depth, in a natural setting, with a focus on context and using a combination of methods.

- The authors conducted an embedded single case study (see table 3).22 44-46

The case was bounded by examining the relevant activities in the teaching institution, and the outcomes of the training in the host training institution for the trainees, instructors and clinicians who would be in a position to comment on the impact of the training.

- The study protocol included data collection during three time periods: two initial waves of data collection in years 1 and 2 with participating residents, and a third year of follow-up data collection to assess the impact of training.

- The researchers implemented four data collection arms: (1) post-training evaluations from the residents and instructors; (2) followup semistructured interviews with residents; (3) semistructured interviews with key informants (nurses and medical assistants); and (4) a web-based questionnaire given to residents.

- The authors used a linear type of analysis logically organised by emergent themes.

- The authors inductively analysed the data guided by the research questions and conducted a thematic analysis.

- The authors conducted descriptive statistics. The specific programme used was not reported.

- The analytical techniques focused on pattern matching between training and skills used, and explanation for the outcomes. 


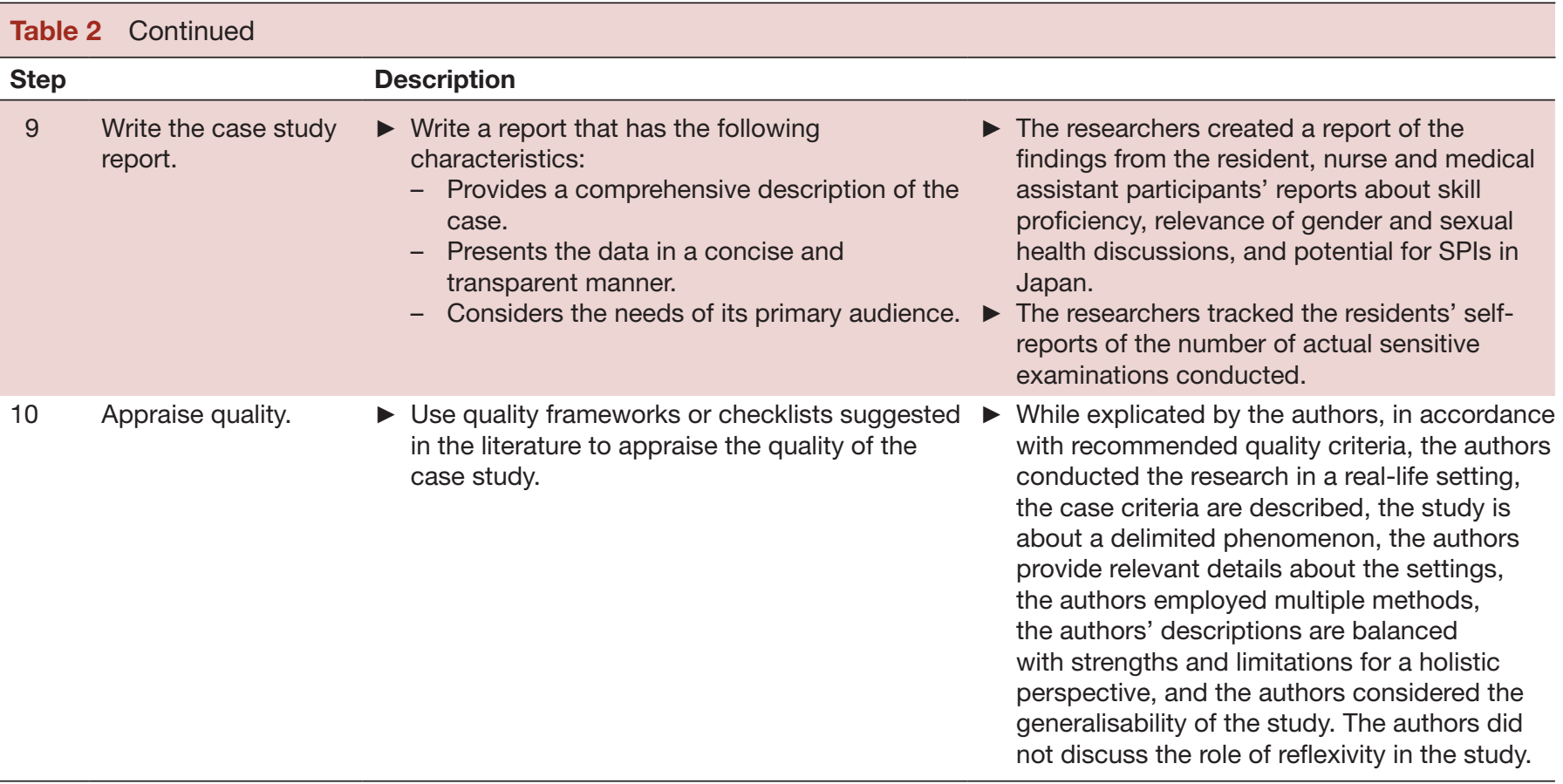

SPI, standardised patient instructor.

a finding may occur' (p583). ${ }^{25}$ In type 4 embedded multiple case design, a variant of the holistic multiple case design, researchers perform a detailed examination of the subunits of each programme, rather than just examining each case as a whole.

\section{Step 5. Define the boundaries of the case(s) and select the case(s)}

Miles $e t a t^{26}$ define a case as 'a phenomenon of some sort occurring in a bounded context' (p28). What is and is not the case and how the case fits within its broader context should be explicitly defined. As noted in step 4, this step may occur before choice of the case study type, and the process may actually occur in a back-and-forth fashion. A case can entail an individual, a group, an organisation, an institution or a programme. In this step, researchers delineate the spatial and temporal boundaries of the case, that is, "when and where it occurred, and when and what was of interest' (p390). ${ }^{9}$ Aside from ensuring the coherence and consistency of the study, bounding the case ensures that the planned research project is feasible in terms of time and resources. Having access to the case and ensuring ethical research practice are two central considerations in case selection. ${ }^{1}$

\section{Step 6. Prepare to collect data}

Before beginning the data collection, researchers need a study protocol that describes in detail the methods of data collection. The protocol should emphasise the coherence between the data collection methods and the research questions. According to Yin, ${ }^{3}$ a case study protocol should include (1) an overview of the case study, (2) data collection procedures, (3) data collection questions and (4) a guide for the case study report. The protocol should be sufficiently flexible to allow researchers to make changes

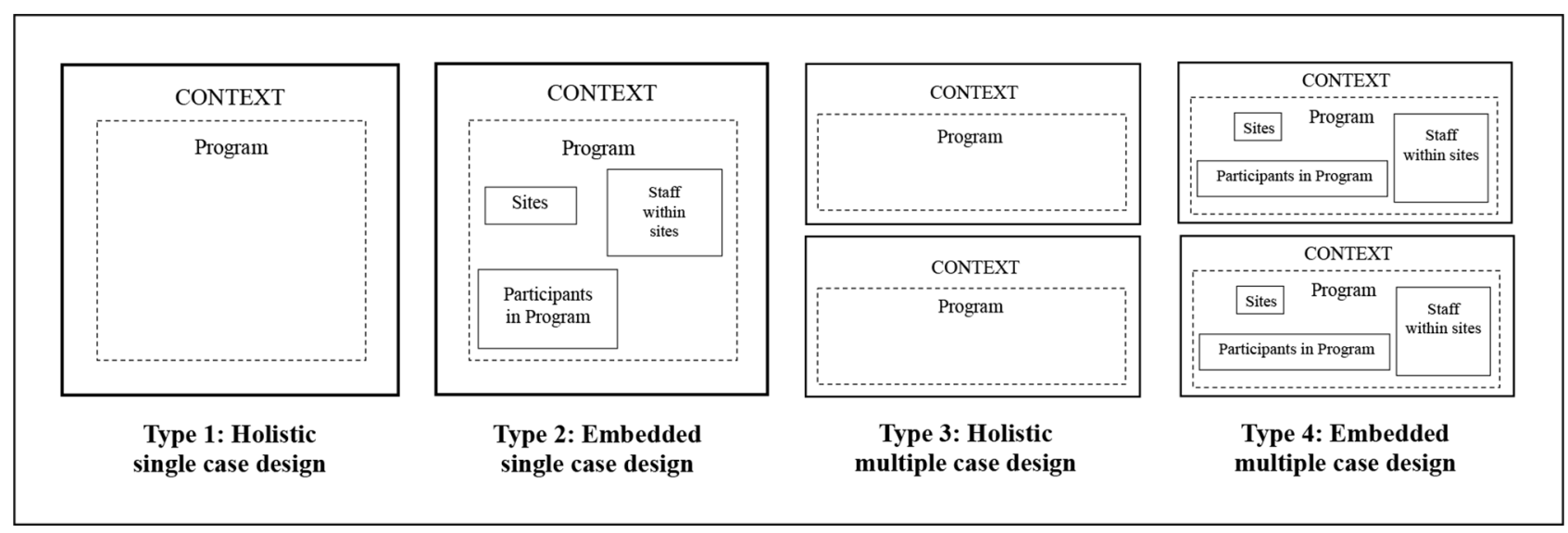

Figure 1 Types of case study designs. ${ }^{321}$ 
Table 3 Examples of published studies using the four types of case study designs suggested by Yin $^{3}$

\begin{tabular}{lll}
\hline Study example & $\begin{array}{l}\text { Type of case study } \\
\text { design }\end{array}$ & Study aim \\
\hline${\text { Little et } a l^{44}}^{\text {Holistic single case. }}$ & $\begin{array}{l}\text { To evaluate the feasibility and } \\
\text { acceptability of a prenatal visit } \\
\text { programme for Japanese women } \\
\text { with limited English skills. }\end{array}$ \\
Shultz et $a l^{22}$ & $\begin{array}{l}\text { Embedded single } \\
\text { case. }\end{array}$ & $\begin{array}{l}\text { To evaluate the perceived } \\
\text { feasibility and impact of an SPI } \\
\text { programme providing training in } \\
\text { sexual healthcare examinations } \\
\text { to Japanese family medicine } \\
\text { residents. }\end{array}$ \\
\hline
\end{tabular}

$\begin{array}{lll}\text { Peterson et } \mathrm{al}^{45} & \begin{array}{l}\text { Holistic multiple } \\ \text { case. }\end{array} & \begin{array}{l}\text { To identify and describe factors } \\ \text { associated with the use of } \\ \text { prevention research in seven } \\ \text { public health programmes. }\end{array} \\ \text { Shea et } \text { al }^{46} & \begin{array}{l}\text { Embedded multiple } \\ \text { case. }\end{array} & \begin{array}{l}\text { To explore factors considered } \\ \text { by primary care providers when } \\ \text { assessing the added value } \\ \text { of a health-related quality-of- } \\ \text { life information technology } \\ \text { application for geriatric patients. }\end{array} \\ & \end{array}$

Methodological features

Survey and interview data were collected from women attending the programme. The programme (ie, the case) was the sole unit of analysis of the study.

Quantitative and qualitative data were gathered from groups of participants directly involved with the programme (ie, trainers in the programme and Japanese residents attending the programme) or whose work was affected by the outcomes of the programme (ie, medical and nursing staff at the residents' workplace). The programme (ie, the case) was the core unit of analysis of the study and the groups of participants were subunits of analysis in the programme.

Seven programmes were compared in terms of the characteristics of research utilisation, including related barriers and facilitators. Archival, observational and interview data were collected from stakeholders involved in the design, implementation and evaluation of the programme. Each programme (ie, cases) constituted a unit of analysis of the study.

Three primary care practices were examined using quantitative and qualitative data sources, such as surveys, observations, audio recordings and semistructured interviews. Data were collected from several groups of participants, including providers, clinical and administrative staff, and patients. The three primary care practices (ie, cases) were the core units of analysis of the study and the groups of participants were subunits embedded within the practices.

SPI, standardised patient instructor.

depending on the context and specific circumstances surrounding each data collection method.

\section{Step 7. Collect and organise the data}

While case study is often portrayed as a qualitative approach to research (eg, interviews, focus groups or observations), case study designs frequently rely on multiple data sources, including quantitative data (eg, surveys or statistical databases). A growing number of authors highlight the ways in which the use of mixed methods within case study designs might contribute to developing 'a more complete understanding of the case' (p902), ${ }^{21}$ shedding light on 'the complexity of a case' (p118) ${ }^{27}$ or increasing 'the internal validity of a study' (p6). ${ }^{1}$ Guetterman and Fetters $^{21}$ explain how a qualitative case study can also be nested within a mixed methods design (ie, be considered the qualitative component of the design). An interesting strategy for organising multiple data sources is suggested by Yin. ${ }^{3} \mathrm{He}$ recommends using a case study database in which different data sources (eg, audio files, notes, documents or photographs) are stored for later retrieval or inspection. See guidance from Creswell and Hirose ${ }^{28}$ for conducting a survey and qualitative data collection in mixed methods and DeJonckheere ${ }^{29}$ on semistructured interviewing.

\section{Step 8. Analyse the data}

Bernard and Ryan ${ }^{30}$ define data analysis as 'the search for patterns in data and for ideas that help explain why these patterns are there in the first place' (p109). Depending on the case study design, analysis of the qualitative and quantitative data can be done concurrently or sequentially. For the qualitative data, the first step of the analysis involves segmenting the data into coding units, ascribing codes to data segments and organising the codes in a coding scheme. ${ }^{31}$ Depending on the role of theory in the study, an inductive, data-driven approach can be used where meaning is found in the data, or a deductive, concept-driven approach can be adopted where predefined concepts derived from the literature, or previous research, are used to code the data. ${ }^{32}$ The second step involves searching for patterns across codes and subsets of respondents, so major themes are identified to describe, explain or predict the phenomenon under study. Babchuk ${ }^{33}$ provides a step-bystep guidance for qualitative analysis in this issue. When conducting a single case study, the within-case analysis yields an in depth, thick description of the case. When the study involves multiple cases, the cross-comparison analysis elicits a description of similarities and divergence between cases and may generate explanations and theoretical predictions regarding other cases. ${ }^{26}$ 
For the quantitative part of the case study, data are entered in statistical software packages for conducting descriptive or inferential analysis. Guetterman ${ }^{34}$ provides a step-by-step guidance on basic statistics. In case study designs where both data strands are analysed simultaneously, analytical techniques include pattern matching, explanation building, time-series analysis and creating logic models (p142-167). ${ }^{3}$

\section{Step 9. Write the case study report}

The case study report should have the following three characteristics. First, the description of the case and its context should be sufficiently comprehensive to allow the reader to understand the complexity of the phenomena under study. ${ }^{35}$ Second, the data should be presented in a concise and transparent manner to enable the reader to question, or to re-examine, the findings. ${ }^{36}$ Third, the report should be adapted to the interests and needs of its primary audience or audiences (eg, academics, practitioners, policy-makers or funders of research). Yin ${ }^{3}$ suggests six formats for organising case study reports, namely linear-analytic, comparative, chronological, theory building, suspense and unsequenced structures. To facilitate case transferability and applicability to other similar contexts, the case study report must include a detailed description of the case.

\section{Step 10. Appraise quality}

Although presented as the final step of the case study process, quality appraisal should be considered throughout the study. Multiple criteria and frameworks for appraising the quality of case study research have been suggested in the literature. Yin ${ }^{3}$ suggests the following four criteria: construct validity (ie, the extent to which a study accurately measures the concepts that it claims to investigate), internal validity (ie, the strength of the relationship between variables and findings), external validity (ie, the extent to which the findings can be generalised) and reliability (ie, the extent to which the findings can be replicated by other researchers conducting the same study). Yin $^{37}$ also suggests using two separate sets of guidelines for conducting case study research and for appraising the quality of case study proposals. Stake ${ }^{4}$ presents a 20-item checklist for critiquing case study reports, and Creswell and Poth $^{38}$ and Denscombe ${ }^{39}$ outline a number of questions to consider. Since these quality frameworks have evolved from different disciplinary and philosophical backgrounds, the researcher's approach should be coherent with the epistemology of the study. Figure 2 provides a quality appraisal checklist adapted from Creswell and Poth ${ }^{38}$ and Denscombe. ${ }^{39}$

\section{DISCUSSION}

The challenges to conducting case study research include rationalising the literature based on literature review, writing the research questions, determining how to bound the case, and choosing among various case study purposes and designs. Factors held in common with other methods include analysing and presenting the findings, particularly with multiple data sources.

\section{Other resources}

Resources with more in depth guidance on case study research include Merriam, ${ }^{17}$ Stake ${ }^{4}$ and Yin. ${ }^{3}$ While each

- Is the study conducted in a real-life setting?

- Are the case selection criteria clearly described and well justified?

- Is the case an instance of a clearly delimited social phenomenon (i.e., event, individual, group, organization, program)?

- Are the boundaries and time limits of the case clearly identified?

- Are the case and its setting described in detail?

- Have the key thematic issues been highlighted?

- Are multiple methods and data sources used appropriately?

- Does the study provide a holistic perspective?

- Have the researchers considered the extent and implications of generalizing the findings?

- Has researcher reflexivity been considered?

Figure 2 Checklist for evaluating the quality of a case study. ${ }^{3839}$ 
reflects a different perspective on case study research, they all provide useful guidance for designing and conducting case studies. Other resources include Creswell and Poth, ${ }^{38}$ Swanborn $^{2}$ and Tight. ${ }^{40}$ For mixed methods case study designs, Creswell and Clark, ${ }^{27}$ Guetterman and Fetters, ${ }^{21}$ Luck et $a l^{6}{ }^{6}$ and Plano Clark et $a l^{41}$ provide guidance. Byrne and Ragin's ${ }^{42}$ The SAGE Handbook of Case-Based Methods and Mills et al $\mathrm{s}^{43}$ Encyclopedia of case study research provide guidance for experienced case study researchers.

\section{CONCLUSIONS}

Family medicine and community health researchers engage in a wide variety of clinical, educational, research and administrative programmes. Case study research provides a highly flexible and powerful research tool to evaluate rigorously many of these endeavours and disseminate this information.

Acknowledgements The authors would like to acknowledge the help of Dick Edelstein and Marie-Hélène Paré in editing the final manuscript.

Contributors SF and MDF conceived and drafted the manuscript, and approved the final version of the manuscript.

Funding The authors have not declared a specific grant for this research from any funding agency in the public, commercial or not-for-profit sectors.

Competing interests None declared.

Patient consent for publication Not required.

Provenance and peer review Not commissioned; internally peer reviewed.

Open access This is an open access article distributed in accordance with the Creative Commons Attribution Non Commercial (CC BY-NC 4.0) license, which permits others to distribute, remix, adapt, build upon this work non-commercially, and license their derivative works on different terms, provided the original work is properly cited, appropriate credit is given, any changes made indicated, and the use is non-commercial. See: http://creativecommons.org/licenses/by-nc/4.0

\section{REFERENCES}

1. Crowe S, Cresswell K, Robertson A, et al. The case study approach. BMC Med Res Methodol 2011;11:1-9.

2. Swanborn P. Case study research: what, why, and how? Thousand Oaks, CA: Sage, 2010.

3. Yin R. Case study research: design and methods. 5th edn. Thousand Oaks, CA: Sage, 2014

4. Stake R. The art of case study research. Thousandthousand Oaksoaks. CA: Sage, 1995.

5. Walshe CE, Caress AL, Chew-Graham C, et al. Case studies: a research strategy appropriate for palliative care? Palliat Med 2004;18:677-84.

6. Luck L, Jackson D, Usher K. Case study: a bridge across the paradigms. Nurs Inq 2006;13:103-9.

7. Ford L, Golden M, Ray E. The case study in health communication research. In: Whaley B, ed. Research methods in health communication: principles and application. New York: Routledge, 2014.

8. Keen J, studies C. In: Pope C, Mays N, editors.. In: Qualitative research in health care. 3rd edn. Oxford: Blackwell, 2006: 112-20.

9. Tight M. Case study research. In: Wyse D, Selwyn N, Smith E, et al, eds. The BERA/SAGE Handbook of educational research. London: Sage, 2017: 376-94.

10. Adelman C, Eurepos G, Eurepos G, et al. Chicago School. In: Mills A, Eurepos G, Wiebe E, et al, eds. Encyclopedia of case study research. Thousand Oaks, CA: Sage, 2010: 140-4.

11. Blatter J. Case study. In: Given LM, ed. The SAGE encyclopedia of qualitative research methods. Thousand Oaks, CA: Sage, 2008: 68-71.
12. Stark S, Torrance H. Case study. In: Somekh B, Lewin C, eds. Research methods in the social sciences. London: Sage, 2005: 33-40.

13. Platt J. "Case Study" in American Methodological Thought. Current Sociology 1992;40:17-48.

14. Lincoln YS, Guba EG. Judging the quality of case study reports. Int $J$ Qual Stu Edu 1990;3:53-9.

15. Eisenhardt KM. Building theories from case study research. Acad Manage Rev 1989;14:532-50.

16. Yin RK. The case study crisis: some answers. Adm Sci Q 1981;26:58-65.

17. Merriam S. Qualitative research and case study applications in education. San Francisco, CA: Jossey-Bass, 1998.

18. Yin R. Case study research: design and methods. Beverly Hills, CA Sage, 1984.

19. Yazan B. Three approaches to case study methods in education: Yin, Merriam, and stake. The Qualitative Report 2015;20:134-52.

20. Hijmans E, Wester F. Comparing the case study with other methodologies. In: Mills A, Eurepos G, Wiebe E, eds. Encyclopedia of case study research. Thousand Oaks, CA: Sage, 2010: 176-9.

21. Guetterman TC, Fetters MD. Two methodological approaches to the integration of mixed methods and case study designs: a systematic review. Am Behav Sci 2018;62:900-18.

22. Shultz CG, Chu MS, Yajima A, et al. The cultural context of teaching and learning sexual health care examinations in Japan: a mixed methods case study assessing the use of standardized patient instructors among Japanese family physician trainees of the Shizuoka family medicine program. Asia Pac Fam Med 2015;14.

23. Boote DN, Beile P. Scholars before researchers: on the centrality of the dissertation literature review in research preparation. Educ Res 2005;34:3-15.

24. Fraenkel J, Wallen $\mathrm{N}$, Hyun $\mathrm{H}$. How to design and evaluate research in education. 5th edn. New York: McGraw-Hill, 2012.

25. Chmiliar L. Multiple-case designs. In: Eurepos G, Mills A, Eurepos G, eds. Encyclopedia of case study research. Thousand Oaks, CA: Sage, 2010: 582-4.

26. Miles M, Huberman A, Saldaña J. Qualitative data analysis: a methods sourcebook. 3rd edn. Thousand Oaks, CA: Sage, 2014.

27. Creswell J, Clark P V. Designing and conducting mixed methods research. 3rd edn. Thousand Oaks, CA: Sage, 2018.

28. Creswell J, Hirose M. Approach to mixed methods survey design. Fam Med Comm Health 2019.

29. DeJonckheere M. Fundamentals of semi-structured interviews. Fam Med Comm Health 2019.

30. Bernard H, Ryan G. Analyzing qualitative data: systematic approaches. Thousand Oaks CA: Sage, 2010.

31. Tesch R. Qualitative research: analysis types and software tools. Abingdon: Routledge Falmer, 1990.

32. Gibbs G. Analysing qualitative data. London: Sage, 2007.

33. Babchuk W. Fundamentals of qualitative analysis. family medicine and community health, 2019.

34. Guetterman T. Fundamentals of biostatistical analysis. Fam Med Comm Health 2019.

35. Baxter P, Jack S. Qualitative case study methodology: study design and implementation for novice researchers. The Qualitative Report 2008:13:544-99.

36. Gray D. Doing research in the real world. London: Sage, 2004.

37. Yin RK. Enhancing the quality of case studies in health services research. Health Serv Res 1999;34:1209-24.

38. Creswell J, Poth C. Qualitative inquiry and research design: choosing among five approaches. 4th edn. Thousand Oaks, CA: Sage, 2018.

39. Denscombe M. The good research guide for small-scale social research projects. 4th edn. Berkshire: Open University Press, 2010.

40. Tight M. Understanding case study research: Small-scale research with meaning. London: Sage, 2017.

41. Plano Clark VL, Foote LA, Walton JB, et al. Intersecting mixed methods and case study research: design possibilities and challenges. Int J Mult Res Approaches 2018;10:14-29.

42. Byrne D, Ragin C, eds. The SAGE handbook of case-based methods. London: Sage, 2009.

43. Mills A, Eurepos G, Wiebe E, eds. Encyclopedia of case study research. Thousand Oaks, CA: Sage, 2010.

44. Little SH, Motohara S, Miyazaki K, et al. Prenatal group visit program for a population with limited English proficiency. J Am Board Fam Med 2013;26:728-37.

45. Peterson JC, Rogers EM, Cunningham-Sabo L, et al. A framework for research utilization applied to seven case studies. Am J Prev Med 2007;33:S21-S34.

46. Shea CM, Halladay JR, Reed D, et al. Integrating a health-relatedquality-of-life module within electronic health records: a comparative case study assessing value added. BMC Health Serv Res 2012;12. 